\title{
O BATISMO MÍNIMO: MORTE E POESIA EM HILDA HILST
}

\section{THE MINIMUM BAPTISM: DEATH AND POETRY IN HILDA HILST}

\author{
Cleber da Silva Luz ${ }^{1}$ \\ Sandro Adriano da Silva ${ }^{2}$
}

Recebido em: 13 nov. 2019.

Aceito em: 22 fev. 2020.

DOI 10.26512/aguaviva.v5i1.25523

RESUMO: Para Octavio Paz (2012), a poesia evoca uma materialização do sentir, do falar e do viver, nutrida que é pela angústia, tensionada pela ausência e, portanto, própria à interrogação sobre a experiência da perda, da transcendência, da efemeridade, e, no limite, da morte. Pautando-nos em conceitos e em elementos constitutivos do gênero lírico (MOISÉS, 2012); na concepção de poesia e poema (PAZ, 1982); na projeção da forma arquitetônica (BAKHTIN, 1998); na natureza da lírica como criadora de complexos de imagens dotados de pathos (CROCE, 2011), tencionamos apresentar uma análise interpretativa do poema intitulado "XXIII", que integra a obra Da Morte. Odes Mínimas (2003), de Hilda Hilst, identificando os efeitos de sentidos produzidos, a perspectiva, o tom e suas relações com o tema, a partir dos recursos estilísticos presentes no poema, explorando, principalmente, as metáforas do batismo e da morte. Metáforas responsáveis pela expressão das emoções subjetivas, das condições da alma e do pensamento, dos sentimentos mais profundos do eu lírico, poeticamente elencados e "batizados" por Hilda Hilst.

Palavras-chave: Poesia brasileira. Metáfora. Batismo. Morte. Hilda Hilst.

\begin{abstract}
For Octavio Paz (2012), poetry evokes a materialization of feeling, speaking and living, nourished by anguish, tensioned by absence and therefore proper to the interrogation of the experience of loss, transcendence, ephemerality, and, at the limit, of death. Guiding ourselves in the concepts and constitutive elements of the lyrical genre (MOISÉS, 2012); in the conception of poetry and poem (PAZ, 1982); in the projection of the architectural form (BAKHTIN, 1998); in the nature of the lyric as creator of complexes of images endowed with pathos (CROCE, 2011), we intend to present an interpretative analysis of the poem titled XXIII, that integrates the work Da Morte. Odes Minimas (2003), by Hilda Hilst, identifying the effects of senses produced, perspective, tone and their relation to the theme, from the stylistic resources present in the poem, exploring, mainly, the metaphors of baptism and death. Metaphors

\footnotetext{
${ }^{1}$ Mestrando em Letras (Estudos literários) pela Universidade Estadual de Maringá (UEM). Graduado em Letras (Língua Portuguesa e Inglesa) pela Universidade Estadual do Paraná (Unespar). E-mail: clebersiluz@ gmail.com

${ }^{2}$ Doutorando em Literatura pela Universidade Federal de Santa Catarina (UFSC), Mestrado em Letras pela Universidade Estadual de Maringá - Estudos Literários - (UEM). Especialização em História e Cultura Afrobrasileira e Africana - União Pan-Americana de Ensino (UNIPAN). Graduação em Letras - Português-Inglês Universidade Estadual do Oeste do Paraná (UNIOESTE). Professor-Assistente do Departamento de Letras da Universidade Estadual do Paraná - UNESPAR, campus de Campo Mourão. E-mail: cleber.luz@ unespar.edu.br
} 
responsible for the expression of subjective emotions, conditions of soul and thought, the deeper feelings of the lyrical self, poetically listed and "baptized" by Hilda Hilst.

Keywords: Brazilian poetry. Metaphor. Baptism. Death. Hilda Hilst.

\section{INTRODUÇÃO}

Este artigo apresenta uma análise interpretativa do poema intitulado "XXII", que integra a obra Da Morte. Odes Mínimas (2003), de Hilda Hilst. Para a análise, lançaremos um olhar para as metáforas que batizam e nomeiam a morte, este elemento essencial, causa da angústia e estranhamento, que matiza as dúvidas e as vicissitudes do eu lírico. Esse objeto de espanto a morte - leva o eu poemático às mais profundas buscas do como a enfrentar, do como entendêla e expressá-la. Para que se possa buscar sentidos, respostas, explicações ou ainda o conforto para as estranhezas que a poesia causa ao leitor, a poeta recorre a uma linguagem ambígua, de signos polivalentes, por meio das quais, a morte é um dizer sugerido, mais do que definido, na verdade a mais poética das vivências humanas. As imagens que nutrem o pathos correspondem às metáforas, a partir das quais podemos entender que a poesia está centrada na manifestação do "eu" e no interior do poeta, seus complexos sentimentos e suas intenções (MOISÉS, 1989).

É somente de maneira livre que se pode expressar dor, marcar subjetividade de um eu que sente, confessa e que se faz avesso em sua poesia. Nesse sentido Moisés (1989) afirma que:

O poeta lírico está preocupado com o próprio "eu": "o conteúdo da poesia lírica" é "a maneira como a alma, com seus juízos subjetivos, alegrias e admirações, dores e sensações, toma consciência de si própria no âmago deste conteúdo"; "com efeito, o que interessa antes é antes de tudo é a expressão da subjetividade como tal, do seu exato conteúdo, da alma e dos sentimentos, e não a de um objeto exterior, por muito próximo que seja". (MOISÉS, 1989, p. 230).

O lírico está centrado no eu sozinho, como exercício individual. Nesse sentido, o poema é definido como forma de expressão da poesia, ou seja, o poema é a poesia em pé, é a materialização do sentir, do falar e do viver, uma vez que o lírico funciona como um "exorcismo", como um método de libertação interior, um exercício espiritual, tendo sempre relação com um processo de perda (PAZ, 2012).

Por meio da palavra polivalente o poeta materializa suas vontades e, sendo assim, cria no leitor uma multiplicidade de imagens que reverberam em sua alma a estranheza de encontrarse com a intenção deste. Sobre a palavra e sua construção de imagens e símbolos. Paz (2012) 
tratou que "O homem é um ser que criou a si mesmo ao criar a linguagem. Pela palavra, o homem é a constante produção de imagens e formas verbais rítmicas, é uma prova do caráter simbolizador da fala de sua natureza poética" (PAZ, 2012, p. 42).

Bakhtin, ao tratar da forma literária, distingue: artefato (a obra, o romance) e o objeto estético (todos os valores axiológicos e culturais manifestados no "ato estético"). (BAKHTIN, 2014, p. 44). O objeto estético é uma arquitetônica - em outras palavras, aquilo que resulta quando o material (verbal) realiza um conteúdo e produz um sentido maior. No poema de Hilda Hilst, o eu lírico (a voz que "fala" no poema) expõe um estado de espírito, uma confíssão de como se sente diante de si e da morte; e, tal como as imagens da morte, ele se sente todo fragmentado, dividido. E, para comunicar a essência dessa confissão, a poeta elabora um texto igualmente "fragmentado", cindido, dividido em sete partes, reiterando a imagem/ideia (logopeia), “quando é que vem?”. Eu dividido, poema dividido. Para Bakhtin, só há "arquitetônica" na arte elevada (bem feita). Em outras palavras, não importa somente "o que é dito", mas “como se é dito". (BAKHTIN, 2014, p. 35).

Hilda Hilst, no poema XXIII, faz uso metafórico desses conceitos, ao relacioná-los a seus conhecimentos internalizados sobre o mundo e sobre o ser com os arquétipos da morte, do tempo e da essência dessa condição humana que é a passagem de vida para outro plano espiritual. A poeta faz um rico investimento no trabalho com a linguagem poética, suas metáforas idiossincráticas, as escolhas lexicais, a estrutura sintática, a métrica e as ordenações rítmicas. É dessa forma que Hilda Hilst comunica ao leitor toda a poesia que existiu em seu eu interior.

\section{O poema $X X I I I$, de Hilda Hilst}

Hilda Hilst é considerada, hoje, pela crítica literária, uma das maiores escritoras brasileiras do século XX. Em entrevista, ao ser indagada sobre como nascem seus poemas, ela afirma que, "As emoções sentimentais raramente inspiraram sua poesia, sua poesia nascia do inconformismo, e não porque precisavam nascer". Completa que, "Sua poesia sempre surge de um problema maior - o problema da morte, não no sentido metafísico, mas de tudo quanto possa advir depois de acontecida" (DINIZ, 2013).

A poeta escreveu várias obras durante sua grande carreira. Suas obras mesclam e subvertem a clássica tripartição dos gêneros literários: lírico, épico e dramático. A poeta adota um modo particular de escrever, mistura as características de cada forma e fase da escrita 
literária, criando um modelo moderno de escrita, mas não unicamente, e sempre que possível, ela resgatava as clássicas tradições. Sobre a poeta, Silva (2009) escreveu "Dentro do Universo poético, Hilst combina sons, imagens e palavras, por um meio de linguagem simbólica repleta de um conteúdo emocional, passional, transformador, e que atinge reflexões que revelam a essência do ser humano" (SILVA, 2009, p. 264).

Há na poesia interior de Hilda Hilst, um riquíssimo investimento nas imagens poéticas, nos esquemas rítmicos de cada verso elencado nas estrofes do poema por meio do léxico adotado por ela. Esses recursos são os responsáveis pela causa da estranheza ocorrida nos leitores que, ao viver a experiência de leitura de seus poemas, são estranhamente tocados e tomados pela inquietação que sua poesia evoca. Em relação ao tema perseguido nas Odes mínimas, vale a proposição da poeta, quando afirma que "a verdade é que, diante da morte, a gente nunca está realmente conformada. É por isso que penso que o que me leva a escrever é uma vontade de ultrapassar-me, ir além da mesquinha condição de finitude" (HILST, 2013, p. 30).

O poema XXIII, que analisaremos nesse artigo, integra a obra Da Morte. Odes Mínimas (2003), da autora. Esta obra foi lançada no ano de 1980, temos nesse poema, e se não, nessa obra como um todo, a representação da poesia como exercício espiritual de preparação da alma para o tão esperado fim que é concebido pela ideia da morte. A poesia, nessa obra, é levada, pelo eu lítico, de encontro com a morte, de modo que elas dialoguem e se envolvam. Desse modo, o eu lírico coloca a poesia ao mesmo plano da morte uma vez que esta é inconcebível.

Hilda Hilst, sobre as tentativas de explicação de um poema escreveu que "É triste explicar um poema. É inútil também. Um poema não se explica. É como um soco. E, se for perfeito, te alimenta para toda a vida [...]" (HILST, 2018, p. 19).

É diante desse trecho da poeta, que intentamos apresentar uma análise interpretativa, a partir das metáforas idiossincráticas, a perspectiva, o tom e suas relações com o poema, e os recursos estilísticos utilizados pelo eu lírico, suas produções de sentidos na tentativa de nomear e batizar a morte.

\section{XXIII $^{3}$}

Porque conheço dos humanos

Cara, Crueza,

\footnotetext{
${ }^{3}$ HILST, Hilda. XXIII In: HILST, Hilda. Da morte. Odes mínimas. São Paulo: Globo, 2003, p. 51. (Obras reunidas de Hilda Hilst.).
} 
Te batizo Ventura

Rosto de ninguém

Morte-Ventura

Quando é que vem?

Porque viver na Terra

É sangrar sem conhecer

Te batizo Prisma, Púrpura

Rosto de ninguém

Unguento

Duna

Quando é que vem?

Porque o corpo

É tão mais vivo quando morto

Te batizo Riso

Rosto de ninguém

Sonido

Altura

Quando é que vem? (HILST, 2003, p. 51).

Constituído por um "conjunto de imagens e um sentimento que o anima" (CROCE, 2011, p. 193), o poema de Hilda Hilst reverbera a arcaica e tão atual perquirição sobre a morte. Do como o rosto de ninguém, é metáfora da incerteza do que se espera sem saber. É saber do mundo, da dor e do ser e ainda assim não saber o que virá, quando, e se virá. É ter na incerteza a esperança de uma única certeza, a certeza da morte como unguento das dores, dores do sangrar, do sentir e do ser.

Hilda, ao longo do poema, nos conduz junto a ela em sua busca, em sua ânsia pela morte, vendo na morte senão uma espécie de purificação, uma maneira de viver a vida avessa, que para ela, por conhecer, anseia a morte. O eu lírico, apresenta, ao longo estrofes, uma constante caracterização da morte associando a elementos humanos, o que, de fato, se relaciona à ideia da filosofia sobre ser inconcebível definir a morte em sua totalidade, como afirma Dastur (2002):

[...] poderíamos dizer, da morte, o que a tradição ocidental diz tão bem de Deus: que Ele é "algo cuja grandeza não se pode conceber", não certamente porque ela seria plenitude de ser e perfeição suprema, mas ao inverso, porque "é" absoluta anulação, "objeto" impensável, impossível de ser circunscrita, sobre a qual nenhum domínio jamais foi possível e cuja onipotência sobre nós é semelhante à de um deus único" (DASTUR, 2002, p. 08). 
Na primeira estrofe do poema, formada por uma sextilha, o eu lírico inicia recorrendo à utilização do recurso da anáfora, que fica marcada pela repetição do uso do pronome explicativo Porque no primeiro verso inicial de cada estrofe; este, com tom reflexivo, expõe seus conhecimentos e experiências de vida, seus motivos ou justificativas para a espera do que não se sabe sobre a morte. Ainda no primeiro verso, quando usa as palavras [...] conheço dos humanos, o eu lírico marca sua existência, o que conhece do mundo por meio de suas experiências confirmando o que expõe o pronome explicativo Porque. Neste verso, o substantivo humano aparece com função conotativa, eu lírico faz referência ao próprio ser humano em sua essência, ao homem, a alma, a carne e o osso.

No segundo verso da primeira estrofe, o eu lírico utiliza da polissemia e da metáfora, ao empregar as palavras Cara e Crueza; ambas constroem uma personificação do humano tratado no verso anterior. Cara como metáfora da aparência, do que se pode ver, do que se recebe ou do que se mostra, e o que está na face do ser humano, Crueza como o interno do ser humano, sinônimo de crueldade, derivação de cru, do que está por dentro da Cara, tratando dos humanos como algo incompreensível.

Na construção do poema o eu lírico dá vestígios de que espera algo que lhe alivie desse saber dos humanos, pois saber de "algo" e mesmo assim não ter o que esperar, é muito sofrimento, "algo" este, caracterizado pela morte, pois mesmo que na condição de desconhecida, ela já se faz contrária ao que se é em vida.

No terceiro verso da primeira estrofe, tendo a morte como desconhecida e como esperada, o eu lírico dá nome a ela no emprego da imagem poética Te batizo, como rito de humanização. A metáfora do batismo tem, também, como essência simbólica o rito do batismo como rito de purificação ou de renovação, como tratou Chevalier (2012) o rito do batismo "Era conhecido nos meios essênios, mas também em outras religiões (que associam aos ritos de passagem, especialmente aos de nascimento e morte) [...]" (CHEVALIER, 2012, p. 126).

Neste sentido, podemos afirmar que o batismo, em sua essência, exerce no poema a função de caracterizador da morte como um tempo de renovação da condição de vida com base na existência humana, a morte batizada pelo eu lírico assume características do humano como um rito de imersão.

Associado à condição da morte, estamos num plano do fim, de uma condição de termino de uma fase - vida - e início de outra - a morte, como um início de vida em outro plano -. Segundo Chavelier (2012) todos os passos que se seguem nesse ritual atendem à dupla intenção 
desse ato cerimonial, o de purificar e o de vivificar. A morte, então na condição de batizada, passaria a ser a purificação da vida, e vivificação em outro plano espiritual maior.

Batizando e dando a morte o nome de Ventura, se tem outra metáfora da morte, dando a esta metáfora as características e sentidos de acaso, como a espera de uma sorte futura, de um destino que não se sabe, mas que chega. Seria agora, então, a morte como uma sina nas mãos do destino.

Uma metáfora do incognoscível é marcada no quarto verso da primeira estrofe, Rosto de ninguém aparece marcando uma antítese, pois a palavra rosto tem sentido de face, da cara do ser humano, e ninguém como algo que não existe, formando uma ideia, com conceitos contrários e um tanto ilógicos, mas que corrobora para a formação da carga semântica do verso. O Rosto de ninguém como rosto do ser humano desconhecido, o que se vê em cara, mas se desconhece em sua crueza, o que se pode saber em ver, mas o conhecer em viver é ventura.

No quinto verso da primeira estrofe, tem-se a formação de uma palavra por meio da justaposição, o eu lírico faz uso das palavras Morte e Ventura para formar a palavra MorteVentura, significando que após batizada, a morte passa a ser ventura. O uso da justaposição faz com que nenhuma das palavras perca sua essência, seu significado, morte e ventura agora caminham juntas.

Pensando em um sentimento que converta o negativo em positivo e o nada em ser, há em verdade lugar para o intratável tema da morte (DASTUR, 2002). Morte e Ventura são substantivos que marcam certa oposição entre seus devidos sentidos, morte como fim relacionada a algo negativo, e ventura como uma sorte vindoura, uma espécie de mudança no estado negativo da morte colocando as expectativas ao inominável que virá com a sorte da morte.

No sexto verso da primeira estrofe, o eu lírico se utiliza do recurso da anáfora, marcada pela repetição do verso nas demais estrofes do poema, caracterizando um verso-estribilho, no qual ao retornar ao conteúdo de cada estrofe, reproduz o efeito rítmico de cada estrofe poética, assim integralmente. Há uma Anáfora, marcada pela pergunta retórica Quando é que vem?, com total tom de exaustão, de espera pela morte como alívio do sentir que se tem ao conhecer dos humanos, da espera incerta de sua hora. O eu lírico marca sua ansiedade e busca pela saída do "purgatório" que é viver na terra e, assim, a cada dia conhecer mais dos humanos, o exorcismo do mal do saber. 
A pergunta Quando é que vem?, deixa clara a ansiedade do eu lírico em busca de respostas sobre a hora - tão - esperada da incerta chegada da morte. Relacionando a morte com a ansiedade e inquietude que sua espera causa, Dastur (2002), afirma que:

\begin{abstract}
A inquietação com a alma é inseparável da inquietação com a morte, que se torna inquietação autêntica com a vida; a vida (eterna) nasce desse olhar voltado diretamente para a morte, do triunfo sobre a morte (talvez não seja ela outra coisa além desse 'triunfo') (DASTUR, 2002, p. 34.).
\end{abstract}

Desse modo, relacionando a condição humana com a inquieta realidade da alma, com a irrequietação constante da vida, as experiências adquiridas pelas vivencias do eu lírico colocam a morte, nesse momento, como triunfo maior, como êxito de sua longa, turbulenta e tão ansiada espera. A morte em sua condição maior que a existência humana em vida, se faz, agora, a vitória almejada. A pergunta aparece em sequência de uma série de colocações sobre a vida na terra, o viver do ser e o ser, insiste na tamanha ansiedade e certeza do eu lírico de sua espera pela morte. Desse modo, segundo Guido (2009), “Quando a morte é propalada como a certeza absoluta, o tempo assume o papel do algoz que executa a sentença previamente ditada e a pessoa humana é somente um ser para a morte [...]" (GUIDO, 2009, p. 205).

No início da segunda estrofe formada por uma sétima, temos novamente a anáfora presente no início do verso pelo uso do pronome explicativo porquê. Na sequência, o eu lírico usa a expressão viver na Terra, fazendo referência ao viver e/ou sobreviver na terra e no mundo, mas uma vez deixando metaforizada sua confirmação sobre ter conhecimento do mundo, e das vivencias na terra.

Com o uso de uma metáfora idiossincrática temos a formação do segundo verso da segunda estrofe. O sangrar aparece como metáfora idiossincrática do viver na terra, do dar o sangue para se obter algo, das lutas diárias, do sangue que se dá pelas incertezas, pela ventura de viver e não saber onde se vai chegar, dos tantos rostos de ninguém que se vê a cara e não se vê a crueza.

No terceiro verso da segunda estrofe, assim como no terceiro verso da primeira estrofe, com mais elementos do saber da vida, do existir e do ser, a morte é batizada como prisma no qual há a representação das cores da luz, a cor da luz tem várias cores, metaforizando o fato de que a vida tem muitas passagens, muitos momentos, muitos acontecimentos, e que relacionado ao sangrar no verso anterior, o eu lírico batiza agora a morte personificada metaforicamente como Prisma, Púrpura, cores de vermelho, vermelhos do sangue, do sangue que se dá ao viver na terra. 
A palavra unguento no quinto verso da segunda estrofe tem como símbolo metafórico sua utilização, unguento como símbolo de remédio, como a pomada que se utiliza para amenizar e tornar suportáveis dores, com uso metafórico, pois se refere às dores do sangrar pelo viver, uma dor que neste contexto é simbólica ou variável, de sangrar para sangrar. O unguento como símbolo de força e resistência para suportar e conseguir viver na terra, até que chegue a hora da esperada sorte da morte - .

No sexto verso da segunda estrofe, a palavra Duna é utilizada pelo eu lírico, como extensões de areia, as quais são símbolos da passagem do tempo e das provações. Sendo a Duna uma imensa elevação de areia que se movimenta sem força alguma além da força do vento, que não se sabe, não se mede e que quando o vento vem, ela apenas se move cobrindo e arrastando o que vem pela frente. O incerto é, então, marcado pela certeza do inesperado. Sabemos o que é, como vem, e como ela não é, até que ela venha e se faça em seu nome: morte.

Como no início das duas estrofes anteriores, na terceira estrofe que é formada por uma sétima, o verso inicia-se com a utilização da anáfora por meio do porquê que, neste terceiro momento, reforça todos os afetos apresentados nos versos corridos, seu conhecimento do mundo e dos humanos, seguido pelo sentido de denotação do corpo, pois, faz referência ao corpo do ser humano, a parte física de carne e osso, que carrega a alma. E mesmo que denotativo, tem um fundo metafórico, que trata o corpo como o próprio ser humano em sua essência, corpo, alma e vida.

No segundo verso da terceira estrofe o eu lírico faz uso da antítese, ao utilizar é tão mais vivo quando morto fazendo um jogo entre tempos opostos e/ou contrários, fazendo relação a momentos distintos da vida em uma mesma situação, associando os dois conceitos de forma que se possa obter um sentido mais expressivo para a totalidade poética do verso.

Ainda neste verso, fica clara a visão da morte como algo que, mesmo ainda sem rosto, ou com um rosto desconhecido, se faz melhor que a vida, se faz melhor que o viver. Seria a morte o unguento da vida na terra. Se não é a morte a solução das dores e dos problemas, ao menos a amenização ou a mudança, pois não se sabe qual a ventura da morte, apenas se tem a certeza da não efemeridade do viver na terra, como humano.

No terceiro verso da terceira estrofe, mais uma vez com os vestígios de certeza, do mundo e aproximação do saber da morte, o eu lírico batiza a morte, desta vez, como Riso, o riso como metáfora da felicidade ou da sensação de libertação das dores mundanas quando chegada a hora da morte. O Riso como a ação seguida de algo que faz sorrir, algo que faz bem e é bom em seu existir e acontecer. 
Ainda pensando sobre a ação que desencadeia o riso, podemos relacionar o Riso tratado pelo eu lírico com a ideia de que rimos "somente porque surpreendemos nele uma atitude de homem ou uma expressão humana." conforme escreveu Bergson (1960, p. 18). Desse modo o ato de sorrir está inteiramente ligado à condição humana, a qual é usada a todo o momento pelo eu lírico para a caracterização da morte, a tão almejada.

No quinto verso da terceira estrofe, o eu lírico faz uso da metáfora ao empregar a palavra Sonido, que é sinônimo de som, que faz um paralelo direto com o Riso que aparece no terceiro verso da terceira estrofe, dando um sentido de tom do riso, metáfora do riso de escárnio. Fazendo relação ao sentido ambíguo da palavra Altura, utilizada pelo eu lírico no sexto verso da terceira estrofe, o eu lírico traça uma ideia de algo bom que a morte trás, o riso como marca de chegada a hora esperada.

A palavra Altura é ambígua ao se relacionar com as palavras apresentadas nos versos anteriores. Temos o sentido de altura do som do riso, de entonação e caracterização desse riso como gargalhada ou felicidade extrema. E em outro estado, temos com altura um sinônimo de uma qualidade do que é alto, e/ou do que é profundo, ligadas à ideia da morte pensando no libertar-se do corpo humano, e ter uma vida melhor na morte.

Por fim, no sétimo verso da terceira estrofe o eu lírico repete e marca sua busca e ansiedade pela espera da morte assinalada nos versos finais de cada estrofe do poema pela pergunta retórica Quando é que vem?. Guido (2009), sobre a busca e espera pela morte, afirma: “[...] na tentativa de criar sobre os escombros seu novo habitat humano que sobrevive na poesia; [...], a poeta não teme a morte e dialoga com a vida, porque ela deseja viver, o que está morto lhe angustia, mas ela não teme o que virá: a morte" (GUIDO, 2009, p. 201).

Nesse sentido, o poema XXIII, de Hilda Hilst, faz um diálogo com a vida, com a condição humana, trazendo uma reflexão sobre a morte em seu papel iniciático, de renovação e renascimento. Assim, batizar a morte seria dar uma nova cara à crueza a qual todo o conhecimento e vivencia no mundo o faz saber. A morte, sobretudo, nos revela, pelo poema, que é preciso ir ainda mais longe, e que por ela é que se tem a principal condição para o progresso e para a vida - "É tão mais vivo quando morto" -. Assim, a morte nada mais é que, no sentido da criação poética, o caminho para iniciação e para a renascença. E, nesta relação entre poesia e experiência, "O homem é um ser que se assombra; ao assombrar-se, poetiza, ama, diviniza” (PAZ, 2012, p. 149). Na morte, como na poesia, há assombro, divinização e fetichismo, pois “o poetizar também brota do assombro e o poeta diviniza como o místico e ama como o apaixonado. A poesia é uma revelação da nossa condição original. [...] Essa 
condição é essencialmente defeituosa, pois consiste na contingência e na finitude. O mundo nos amedronta porque nos é apresentado como estranho [...]”. (PAZ, 2012, p. 155-156).

\section{CONSIDERAÇÕES FINAIS}

Ao analisar e interpretar um poema em sua configuração estética, na sua camada imagética, seu corpo lexical e semântico, entramos em contato direto com o sentimento da poesia e do texto que o materializa, estamos em campo de um eu que, assim como sabemos dos humanos, das caras e cruezas, sente. O eu que vive e sangra, o eu do qual não sabemos o que esperar. Uma espécie de catarse acontece, pois, ao entrar na vida do eu que escreve, os sentimentos se fazem vivos provocando descargas de sentidos e emoções, purificando a alma que em sua análise foi utilizada.

\section{REFERÊNCIAS}

BAKHTIN, M. O problema do Conteúdo, do Material e da Forma na Criação Literária. In: BAKHTIN, M. Questões de literatura e de estética: a teoria do romance. Tradução de Aurora Fornoni Bernardini [et al.]. 7.ed. São Paulo: Hucitec, 2014, p. 13-70.

BERGSON, Henri. O Riso: Ensaio sobre a significação do cômico. Tradução de Nathanael C. Caixeiro. 2. ed. Rio de Janeiro: Zahar Editores, 1983.

BIOGRAFIA DE HILDA HILST. Instituto Hilda Hilst. Disponível em: <http://www.hildahilst.com.br.cpweb0022.sevidorwebfacil.com/biografia.php>. Acesso em: 20 mar. 2019.

CHEVALIER, J.; GHEERBRANT, A. Dicionário de símbolos: mitos, sonhos, costumes, gestos, formas, figuras, cores, números. 9. ed. Rio de Janeiro: José Olympio, 1995.

CROCE, Benedetto. Breviário di estética. Aesthetica in nuce. Milano: Adelphi, 2011.

DASTUR, Françoise. A morte: ensaio sobre a finitude. Tradução de Maria Tereza Pontes. Rio de Janeiro: DIFEL, 2002.

GUIDO, Humberto. Pessimismo metafísico e sensibilidade poética: algumas aproximações entre a filosofia e a poesia de Hilda Hilst. In: CINTRA, Elaine Cristina; SOUZA, Enivalda Nunes Freitas. (Org.). Roteiro poético de Hilda Hilst. Uberlândia: EDUFU, 2009. 
HILST, Hilda. XXIII In: HILST, Hilda. Da morte. Odes mínimas. São Paulo: Globo, 2003, p. 51. (Obras reunidas de Hilda Hilst.).

HILST, Hilda. Fico besta quando me entendem. Entrevistas com Hilda Hilst. São Paulo: Biblioteca Azul, 2013.

HILST, Hilda. 132 crônicas: cascos \& carícias e outros escritos. Rio de Janeiro: Nova Fronteira, 2018.

MOISÉS, Massaud. A criação literária: poesia. 11. ed. São Paulo: Cultrix, 1989.

PAZ, Octávio. Poesia e poema. In: PAZ, Octávio. O arco e a lira. Rio de Janeiro: Nova Fronteira, 1982, p. 21-34.

SILVA, Lívia Carolina Alves da Silva. Hilda Hilst: a literatura e a morte. In: CINTRA, Elaine Cristina; SOUZA, Enivalda Nunes Freitas. (Org.). Roteiro poético de Hilda Hilst. Uberlândia: EDUFU, 2009. 